\title{
Characterization of proximal pulmonary arterial cells from chronic thromboembolic pulmonary hypertension patients
}

Rozenn Quarck ${ }^{1 \dagger}$, Marijke Wynants $^{1 \dagger}$, Alicja Ronisz¹, Maria Rosario Sepulveda², Frank Wuytack², Dirk Van Raemdonck ${ }^{3}$, Bart Meyns ${ }^{4}$ and Marion Delcroix ${ }^{1,5^{*}}$

\begin{abstract}
Background: Chronic thromboembolic pulmonary hypertension (CTEPH) is associated with proximal pulmonary artery obstruction and vascular remodeling. We hypothesized that pulmonary arterial smooth muscle (PASMC) and endothelial cells (PAEC) may actively contribute to remodeling of the proximal pulmonary vascular wall in CTEPH. Our present objective was to characterize PASMC and PAEC from large arteries of CTEPH patients and investigate their potential involvement in vascular remodeling.
\end{abstract}

Methods: Primary cultures of proximal PAEC and PASMC from patients with CTEPH, with non-thromboembolic pulmonary hypertension (PH) and lung donors have been established. PAEC and PASMC have been characterized by immunofluorescence using specific markers. Expression of smooth muscle specific markers within the pulmonary vascular wall has been studied by immunofluorescence and Western blotting. Mitogenic activity and migratory capacity of PASMC and PAEC have been investigated in vitro.

Results: PAEC express CD31 on their surface, von Willebrand factor in Weibel-Palade bodies and take up acetylated LDL. PASMC express various differentiation markers including $\alpha$-smooth muscle actin ( $\alpha$-SMA), desmin and smooth muscle myosin heavy chain (SMMHC). In vascular tissue from CTEPH and non-thromboembolic PH patients, expression of $\alpha$-SMA and desmin is down-regulated compared to lung donors; desmin expression is also downregulated in vascular tissue from CTEPH compared to non-thromboembolic PH patients. A low proportion of $\alpha$ SMA positive cells express desmin and SMMHC in the neointima of proximal pulmonary arteries from CTEPH patients. Serum-induced mitogenic activity of PAEC and PASMC, as well as migratory capacity of PASMC, were increased in CTEPH only.

Conclusions: Modified proliferative and/or migratory responses of PASMC and PAEC in vitro, associated to a proliferative phenotype of PASMC suggest that PASMC and PAEC could contribute to proximal vascular remodeling in CTEPH.

Keywords: Chronic Thromboembolic Pulmonary Hypertension, Smooth Muscle Cells, Endothelial cells, Vascular Remodeling

\footnotetext{
* Correspondence: marion.delcroix@uzleuven.be

† Contributed equally

${ }^{1}$ Center for Pulmonary Vascular Diseases, Respiratory Disease Department, Katholieke Universiteit and Universitaire Ziekenhuizen Leuven, Leuven,

Belgium

Full list of author information is available at the end of the article
}

\section{Biomed Central}

(C) 2012 Quarck et al; licensee BioMed Central Ltd. This is an Open Access article distributed under the terms of the Creative Commons Attribution License (http://creativecommons.org/licenses/by/2.0), which permits unrestricted use, distribution, and reproduction in any medium, provided the original work is properly cited. 


\section{Background}

Chronic thromboembolic pulmonary hypertension $(\mathrm{CTEPH})$ is one of the main causes of pulmonary hypertension. CTEPH is characterized by the presence of unresolved thromboemboli associated to fibrous stenosis in the proximal pulmonary arteries. This is resulting in obstruction of proximal pulmonary arteries, increased pulmonary vascular resistance, pulmonary hypertension and progressive right heart failure. It might be caused by single or recurrent pulmonary embolism and/or local formation of thrombi. Proximal obliteration of pulmonary artery, removable by pulmonary endarterectomy (PEA), is the major feature observed in CTEPH [1].

The mechanisms responsible for permanent vessel obstruction remain poorly understood. Proximal lesions share similarities with atherosclerotic plaques, including media thickening and neointima formation [2]. Dysregulation of thrombosis and/or thrombolysis has been described [3-5] as well as an elevated prevalence of inflammatory diseases [6] and mild systemic inflammation [7]. Although vascular remodeling and increased cellularity have been observed in the proximal vascular lesions [8], cellular protagonists have not been identified and respective involvement of both endothelial (PAEC) and smooth muscle cells (PASMC) remains unexplored.

CD31 or PECAM-1 (platelet endothelial cell adhesion molecule-1), a member of the immunoglobulin superfamily, is a transmembrane glycoprotein homogeneously expressed by all human pulmonary EC [9]. von Willebrand Factor (vWF), a glycoprotein mediating platelet adhesion to subendothelium, is mainly produced by endothelial cells where it is stored in the Weibel-Palade bodies [9]. The scavenger receptor expressed by endothelial cells can bind fluorescent DiI-labeled acetylated-LDL (ac-LDL) and is currently used to characterize EC [10]. $\alpha$-smooth muscle actin ( $\alpha$-SMA), desmin and smooth muscle myosin heavy chain (SMMHC) are constitutive proteins of the cytoskeleton involved in the smooth muscle contractile functions and are differentially expressed during smooth muscle differentiation [11].

Enhanced thrombosis appeared not to be the major cause of permanent obstruction of proximal pulmonary arteries. We consequently hypothesized that both PAEC and PASMC derived from the pulmonary arterial wall of CTEPH patients may be active contributors to the physiopathology of CTEPH. Our current objectives were to i) isolate EC and SMC from proximal and (sub)segmental pulmonary arterial wall of CTEPH patients, ii) further characterize them using specifics markers and iii) investigate their proliferating and migrating capacities in vitro.

\section{Methods}

\section{Study population}

Proximal pulmonary vascular material was obtained from i) $16 \mathrm{CTEPH}$ patients, ii) 12 patients with non-thromboembolic pulmonary hypertension $(\mathrm{PH})$ (4 with idiopathic pulmonary arterial hypertension (PAH), 1 with $\mathrm{PAH}$ associated to congenital heart disease and 7 with $\mathrm{PH}$ due to lung diseases) and 15 lung donors. Hemodynamic parameter evaluation was performed by right heart catheterization at the time of lung transplantation or PEA. The study protocol was approved by the Institutional Ethics Committee of the University Hospital of Leuven and participants gave written informed consent.

\section{Tissue collection}

At the time of lung transplantation or PEA, a 2-cm piece of proximal pulmonary artery was collected (Figure 1A $\& 1 B)$. The piece used to isolate cells was free of any thrombotic material and comprised media (only a part regarding PEA samples) and neointima (Figure 1). A piece of segmental or sub-segmental pulmonary artery (diameter 5 to $10 \mathrm{~mm}$ ) was also collected at the time of PEA.

\section{Neointima thickness}

A contiguous piece of artery was fixed in $4 \%$ paraformaldehyde, paraffin-embedded and 7 - $\mu \mathrm{m}$ sections were performed. Sections were deparaffinized and rehydrated. Nuclei and cytoplasm were stained by hematoxylin and eosin, respectively. Staining of elastin was performed using the Verhoeff's van Gieson method. Neointima thickness was measured as the maximal distance from the lumen to the internal elastic lamina.

\section{Isolation of PAEC and PASMC}

Proximal PAEC were obtained by collagenase digestion followed by immunomagnetic separation using antiCD31 monoclonal antibody-labeled beads (Miltenyi Biotec, Utrecht, The Netherlands). Proximal PASMC were isolated using an explant-outgrowth method [12]. All experiments were carried out with cells, which have undergone less than 7 passages.

\section{Cell culture media}

EC were cultured in M199 medium (Life Technologies, Gent, Belgium), supplemented with $20 \%$ fetal bovine serum (FBS), 100 U.mL ${ }^{-1}$ penicillin, $100 \mu \mathrm{g} \cdot \mathrm{mL}^{-1}$ streptomycin, $1.25 \mu \mathrm{g} \cdot \mathrm{mL}^{-1}$ fungizone (Life Technologies), 10 U.mL ${ }^{-1}$ heparin (Aventis, Brussels, Belgium) and $5 \mathrm{ng}$. $\mathrm{mL}^{-1} \alpha$-FGF (R\&D Systems, Abington, UK). SMC were grown in DMEM medium (Life Technologies) supplemented with $10 \%$ FBS, penicillin, streptomycin and fungizone. 


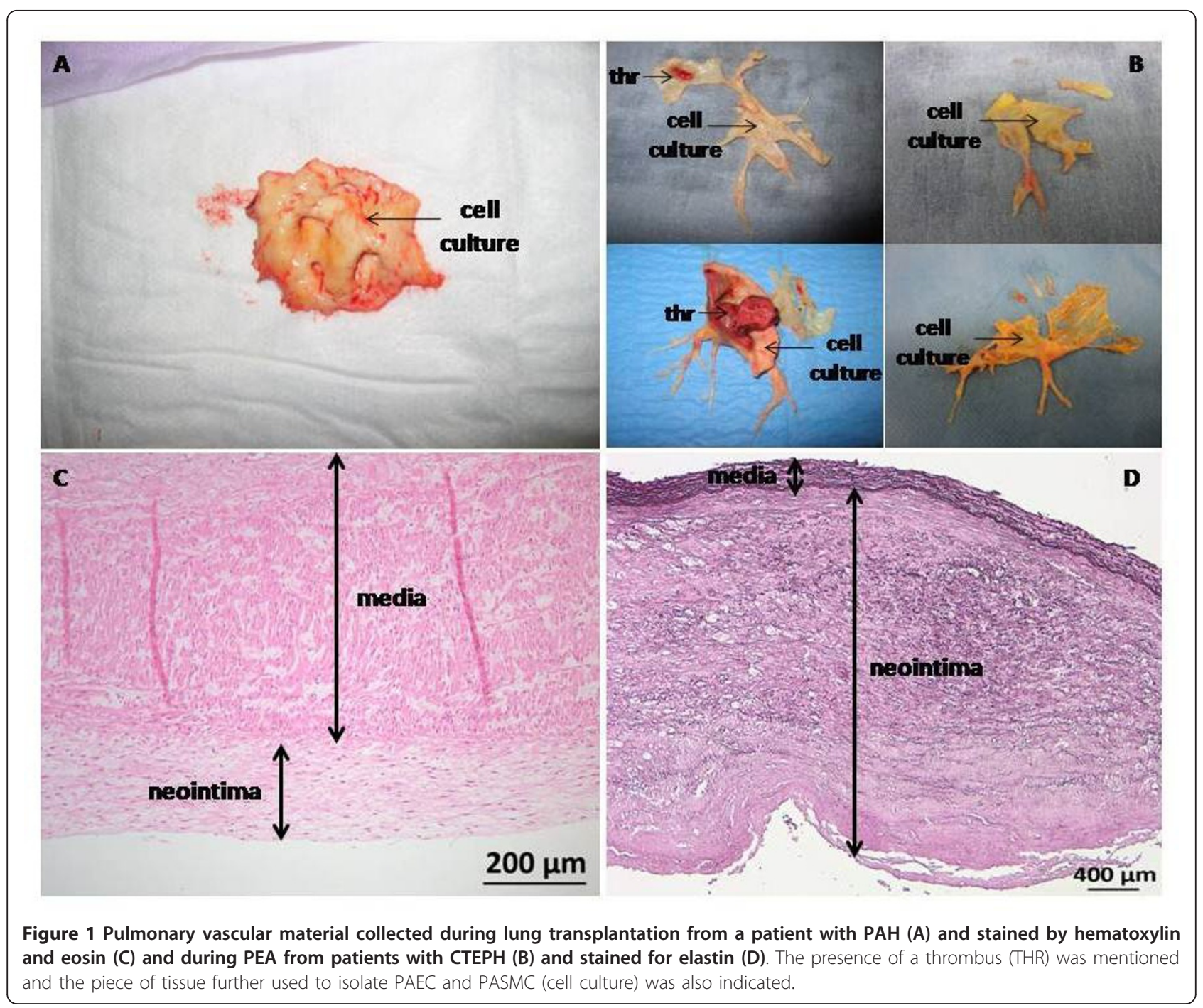

\section{Cell characterization and immunofluorescence on pulmonary arterial tissue}

PAEC phenotype was characterized by labeling cells with diI-Ac-LDL (Tebu, Le Perray en Yvelines, France) and by immunofluorescence using antibodies against CD31 and against vWF (Dako, Heverlee, Belgium). PASMC phenotype was characterized by immunofluorescence using antibodies against $\alpha$-SMA, desmin (Dako) and human SMMHC (Biomedical Technologies, Stoughton, MA). Localization of $\alpha$-SMA, desmin and SMMHC has been performed on $10-\mu \mathrm{m}$ tissue cryosections by immunofluorescence.

\section{Western blotting}

Identification of $\alpha$-SMA and desmin in pulmonary vascular tissue was performed by Western blotting using specific primary antibodies against $\alpha$-SMA or desmin. $\beta$-actin (Abcam, Cambridge, UK) was used as an internal control. Horseradish peroxidase-conjugated donkey anti-rabbit IgG for anti-desmin and anti-mouse IgG (Jackson, Suffolk, UK) for anti- $\alpha$ SMA and anti- $\beta$ actin were used as secondary antibodies. Peroxidase staining was revealed with a chemiluminescence kit (GE Healthcare, Buckinghamshire, UK) and performed with films exposed at room temperature. Protein expression was quantified using the Photoprint imaging system and the BIO-1D software (Vilber Lourmat, Marne-la-Vallée, France).

\section{Proliferation of PASMC and PAEC}

Subconfluent PASMC and PAEC were starved for $24 \mathrm{~h}$ in medium supplemented with $0.2 \%$ FBS. Mitogenic activity of PAEC and PASMC was measured in the presence of $5 \%$ and $10 \% \mathrm{FBS}$, respectively plus $0.5 \mu \mathrm{Ci} \cdot \mathrm{mL}^{-1}$ of $\left[{ }^{3} \mathrm{H}\right]$-thymidine (74 GBq. mmol ${ }^{-1}$; GE Healthcare) for $48 \mathrm{~h}$. Radioactivity incorporation was quantified as 
previously described [13]. $\left[{ }^{3} \mathrm{H}\right]$-thymidine incorporation assays have been validated by cell counting for both PASMC and PAEC.

\section{Migration of PASMC}

Subconfluent PASMC were starved for $24 \mathrm{~h}$ in DMEM supplemented with $0.2 \%$ FBS. PASMC migration was evaluated using a scratch wound assay in the presence of $10 \%$ FBS for 36 hours, as previously described [12].

\section{Statistical analysis}

Database management and statistical analyses were performed using SAS Enterprise Guide 4.1 (SAS Inc., Cary, North Carolina) and GraphPad Prism 4.01 (GraphPad Software Inc., La Jolla, California). Data were expressed as mean \pm SD. Differences between the 2 or 3 groups were analyzed using Student t-test or two-way ANOVA test followed by post-hoc tests. A value of $\mathrm{p} \leq 0.05$ was considered statistically significant. All $\mathrm{p}$ values were for 2-sided tests.

The detailed "Method" section is available in the Additional file 1 .

\section{Results}

The patient characteristics, from which pulmonary vascular material has been collected, are displayed in the Table 1. A table containing individual patient characteristics is available in the Additional file 2.

mPAP, mean pulmonary arterial pressure; RAP, right atrial pressure; TPR, total pulmonary vascular resistance; $\mathrm{CO}$, cardiac output. Hemodynamic parameters have been measured at the time of PEA or lung transplantation.

Mean pulmonary arterial pressure (mPAP) was similar in CTEPH and in non-thromboembolic PH patients, whereas CTEPH patients displayed a significantly higher total pulmonary resistance $(\mathrm{p}=0.04)$ and lower cardiac output ( $\mathrm{p}<0.0001)$ compared to non-thromboembolic $\mathrm{PH}$ patients. The pulmonary vascular material collected consisted in neointima and media (Figure 1C and 1D). However, neointima thickness strongly differed between CTEPH and non-thromboembolic patients with median (range) of $1.54 \mathrm{~mm}(0.46-2.08)$ vs. $0.26 \mathrm{~mm}(0.04-1.34)$, respectively (Mann-Withney, $\mathrm{p}<0.0001$ ).

Table 1 Patient characteristics

\begin{tabular}{|c|c|c|}
\hline & Non-thromboembolic $\mathrm{PH}, n=12$ & CTEPH, $n=16$ \\
\hline Age & $50 \pm 9$ & $59 \pm 13$ \\
\hline Gender, female, \% & 23 & 81 \\
\hline mPAP, mm Hg & $41 \pm 9$ & $42 \pm 12$ \\
\hline $\mathrm{RAP}, \mathrm{mm} \mathrm{Hg}$ & $13 \pm 4$ & $11 \pm 5$ \\
\hline TPR, dyne.sec. $\mathrm{cm}^{-5}$ & $681 \pm 469$ & $1206 \pm 574$ \\
\hline CO, L.min $\min ^{-1}$ & $5.8 \pm 1.9$ & $3.1 \pm 1.0$ \\
\hline
\end{tabular}

\section{PAEC and PASMC characterization}

Subconfluent proximal PAEC isolated from proximal pulmonary arteries of lung donors, patients with nonthromboembolic $\mathrm{PH}$ and CTEPH patients harbor typical "cobblestone" morphology, whereas PASMC display a "hills and valleys" organization (Figure 2).

PAEC derived from lung donors, non-thromboembolic $\mathrm{PH}$ and CTEPH patients expressed CD31 at their surface, contained vWF in Weibel-Palade bodies and are able to take up acetylated LDL (Figure 3).

PASMC populations derived from lung donors, nonthromboembolic PH and CTEPH patients displayed $\alpha$ SMA filaments and expressed desmin and SMMHC (Figure 4).

\section{Differentiation marker expression and distribution in pulmonary arterial tissue}

The expression of $\alpha$-SMA was $50 \%$ and $42 \%$ significantly lower in pulmonary artery tissue of non-thromboembolic $\mathrm{PH}$ and CTEPH patients, respectively, compared to lung donors (Figure 5A). Similarly, expression of desmin was $44 \%$ and $71 \%$ lower in pulmonary artery tissue of non-thromboembolic PH and CTEPH patients, respectively compared to lung donors (Figure $5 B)$. Most $\alpha$-SMA positive cells in the media from lung donors, non-thromboembolic $\mathrm{PH}$ and CTEPH patients express desmin (Figure 6A, B, C) and SMMHC (Figure $6 \mathrm{E}, \mathrm{F}, \mathrm{G})$, whereas only a low proportion of SMC in the neointima from CTEPH patients were co-stained for $\alpha$ SMA and desmin (Figure 6D) or $\alpha$-SMA and SMMHC (Figure 6H).

\section{PAEC and PASMC proliferation and migration}

In the presence of $10 \% \mathrm{FBS}$, CTEPH-PASMC mitogenic activity was significantly increased by $220 \%$ compared to PH-PASMC (48\%) and to donor-PASMC (16\%) (Figure $7 \mathrm{~A})$. In the presence of $10 \% \mathrm{FBS}, \mathrm{CTEPH}-\mathrm{PASMC}$ migration capacity was significantly increased by $126 \%$ compared to PH-PASMC (54\%) and to donor-PASMC (3\%) (Figure 7B). In the presence of 5\% FBS, CTEPHPAEC mitogenic activity was significantly increased (by 120\%) compared to PH-PAEC (26\%) and to donorPAEC (Figure 7C).

\section{Cellular composition of (sub)segmental pulmonary arteries in CTEPH patients}

Staining of a sub-segmental pulmonary artery with $\alpha$ SMA (Figure 8A) and CD31 (Figure 8B) antibodies showed a mild neointima (Figure $8 \mathrm{~A}$ ) and an intact endothelium (Figure 8B). In the presence of 5 and 10\% FBS, mitogenic activity of PAEC and PASMC isolated from segmental or sub-segmental pulmonary arteries of CTEPH patients was increased by $184 \%$ and by $156 \%$, respectively (Figure $8 \mathrm{C}$ and $8 \mathrm{D}$ ). 


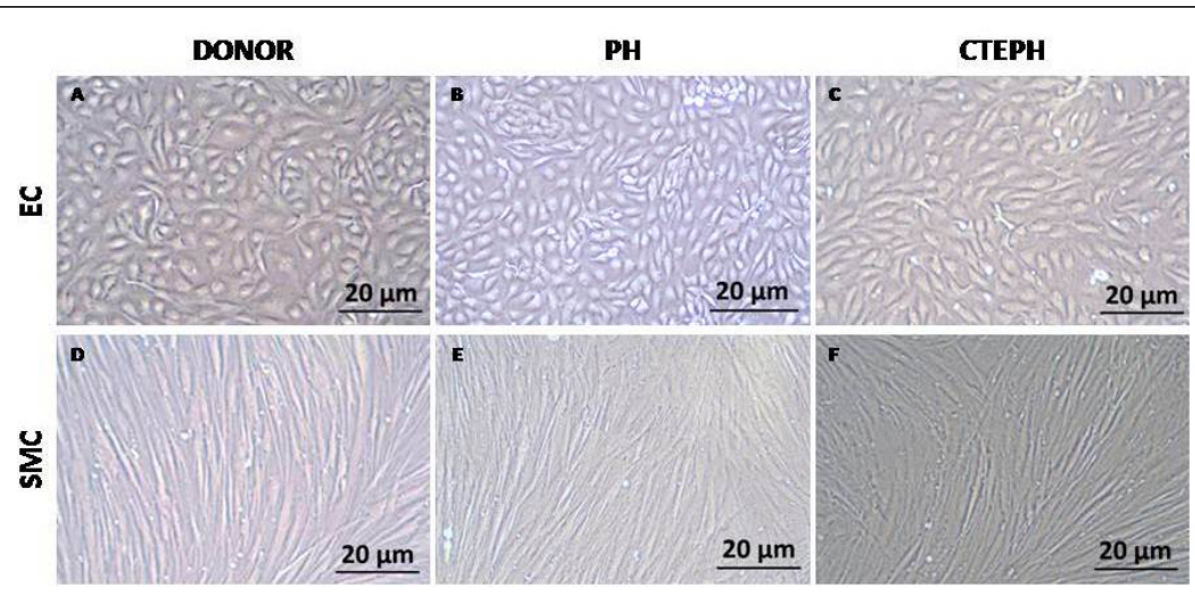

Figure 2 Proximal PAEC and PASMC. Subconfluent PAEC (A, B, C) and PASMC (D, E, F) isolated from proximal pulmonary arteries of lung donors (A, D), non-thrombembolic PH patients (B, C) and from CTEPH patients (C, F).

\section{Discussion}

The aim of the present study was to characterize PASMC and PAEC isolated from large arteries of CTEPH patients and to investigate a potential role of both PASMC and PAEC in the vascular remodeling resulting in permanent obstruction of large pulmonary arteries in CTEPH patients. Our results reveal that, in CTEPH patients, smooth muscle differentiation markers were down-regulated in proximal pulmonary vascular tissue and that pulmonary vascular cells had enhanced proliferative and migratory capacities in vitro, suggesting a potential contribution of PASMC and PAEC to vascular remodeling in proximal pulmonary arteries in CTEPH.

The use of primary cell cultures implies a selection of cells with enhanced growth potential. However, both

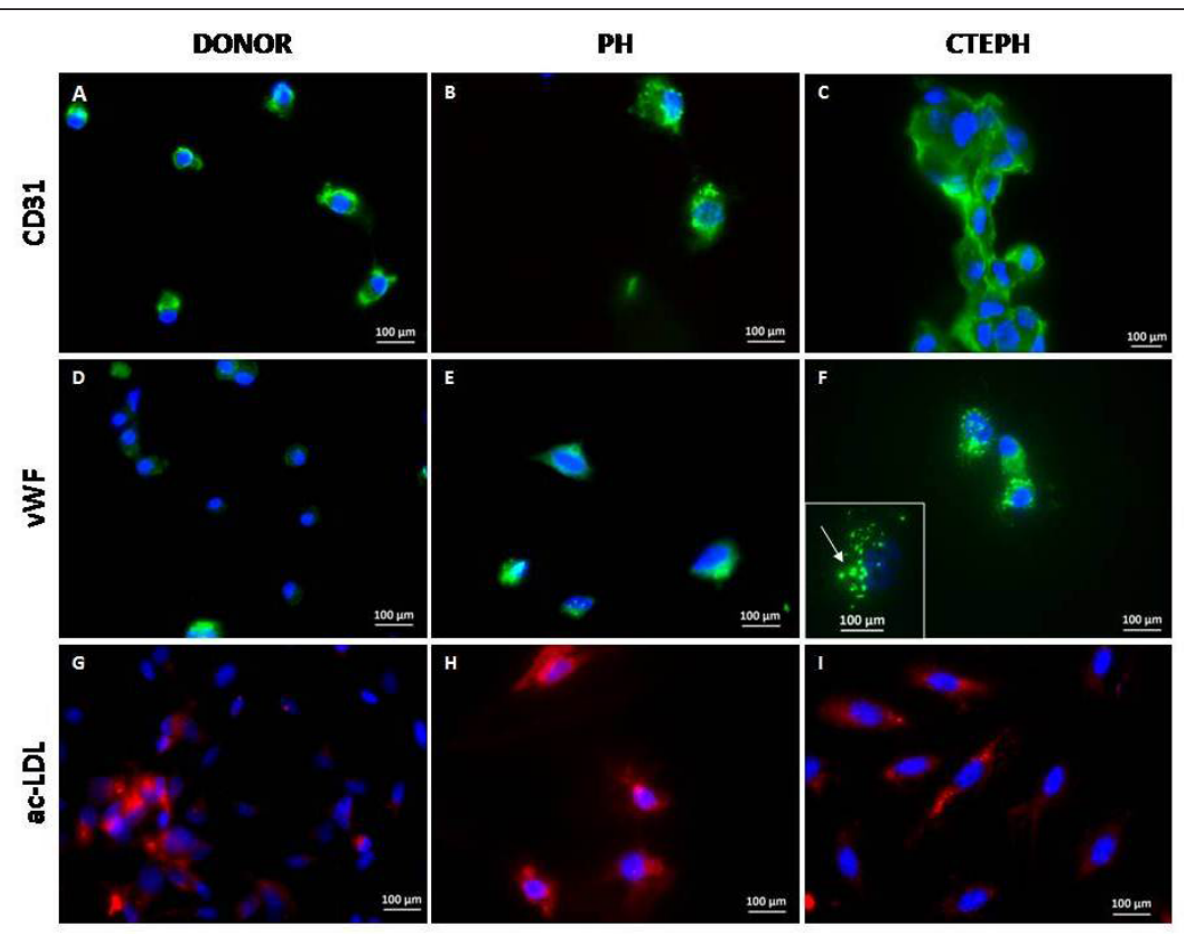

Figure 3 PAEC characterization. Proximal PAEC derived from lung donors $(A, D, G)$, non-thromboembolic PH patients $(\mathbf{B}, \mathbf{E}, \mathbf{H})$ and $C T E P H$ patients $(\mathbf{C}, \mathbf{F}, \mathbf{I})$ were immuno-labeled with antibodies raised against CD31 (A, B, C) and VWF (D, E, F) and stained with Dil-Ac-LDL (G, H, I). Nuclei were counterstained using DAPI (blue). Insert $\mathbf{F}$, the arrow indicates the presence of Weibel-Palade bodies where vWF is stored. 

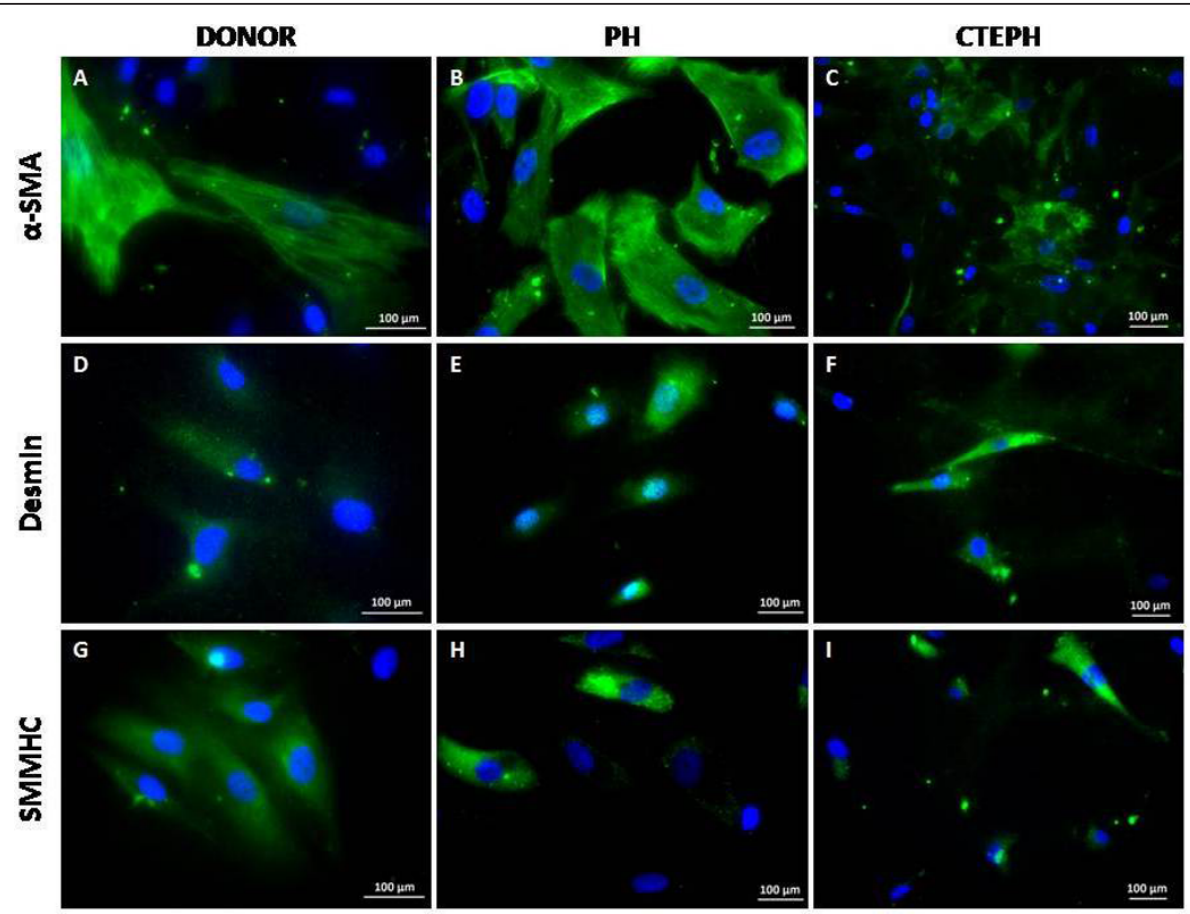

Figure 4 PASMC characterization. Proximal PASMC derived from lung donors (A, D, G), non-thromboembolic PH patients $(\mathbf{B}, \mathbf{E}, \mathbf{H})$ and $C T E P H$ patients $(\mathbf{C}, \mathbf{F}, \mathbf{I})$ were stained with antibodies raised against $\alpha$-SMA $(\mathbf{A}, \mathbf{B}, \mathbf{C})$, desmin $(\mathbf{D}, \mathbf{E}, \mathbf{F})$ and SMMHC $(\mathbf{G}, \mathbf{H}, \mathbf{I})$. Nuclei were counterstained using DAPI (blue).

CTEPH and PH cells were isolated following the same protocol and all experiments were performed with cells at a low number of passages. PEA material usually consists of thrombotic and fibrotic material obstructing the main pulmonary arteries and $40 \%$ of the PEA material we have collected did not harbor any visible thrombotic material. However, the material used to establish primary cell culture was free of any thrombotic material and comprises a part of the media and a thickened neointima. Proximal pulmonary arteries isolated from non-thomboembolic PH patients and from lung donors comprise the whole media and a moderately thickened

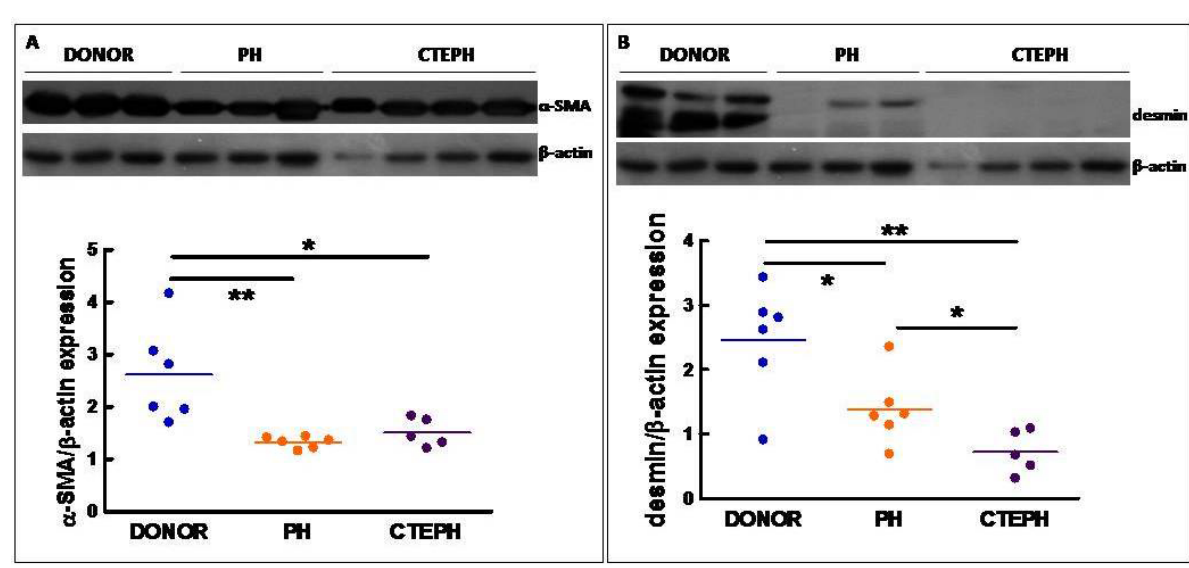

Figure 5 Expression of SMC differentiation markers in pulmonary arteries. Frozen pieces of main pulmonary artery were homogenized, lysed, $100 \mu \mathrm{g}$ of protein samples were submitted to SDS-PAGE and electroblotted. Immunodetection of $\alpha$-SMA (A), desmin (B) and $\beta$-actin (A, B) was carried out by Western blotting using specific antibodies. Protein molecular mass was estimated in kDa using standard markers. Protein expression was quantified by Western blotting densitometry. Results are expressed as the ratio of the band volume of $\alpha$-SMA or desmin to that of $\beta$-actin. Donors $(n=6), C T E P H(n=5)$ and PH $(n=6)$. PH group: circle, PAH; triangle, non PAH-PH. (A) ANOVA, $p=0.003 ;{ }^{*} p<0.05 ;{ }^{* *} p<$ 0.01. (B) ANOVA, $p=0.002 ;{ }^{*} p<0.05 ;{ }^{* *} p<0.01$. 


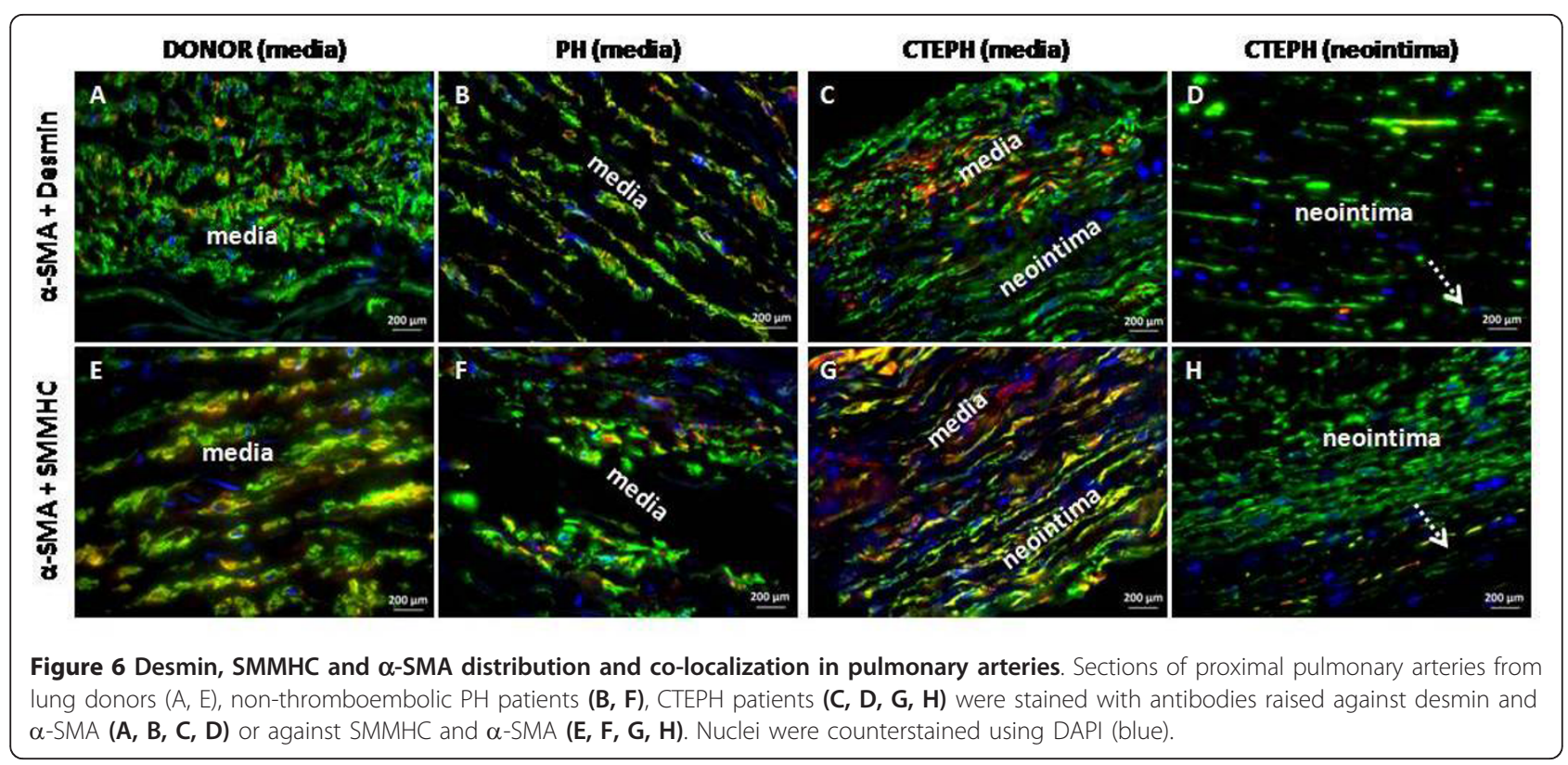

intima. Consequently, in all groups of patients PAEC and PASMC have been isolated from the vascular wall and not from the thrombus. Moreover, despite exposure to similarly high pressures in CTEPH and non-thromboembolic $\mathrm{PH}$, pulmonary vascular cells from nonthromboembolic $\mathrm{PH}$ patients harbor similar proliferative and migratory properties as those from lung donors, who had no PH. Finally, while sub-segmental pulmonary arteries from CTEPH patients displayed only mild neointima thickening and intact endothelium by contrast to proximal arteries, both PASMC and PAEC harbored enhanced proliferative capacities similar to that observed in proximal pulmonary arteries.

\section{Pulmonary vascular cell characterization}

Dysregulation of thrombosis and thrombolysis observed in some patients with CTEPH [5] is not sufficient to explain the intraluminal thrombus organization and fibrous vessel obliteration. Moreover, proximal pulmonary vessel remodeling may even occur without evidence of any clot formation [14]. Increased cellularity has been observed in proximal vascular lesions [8], but cellular

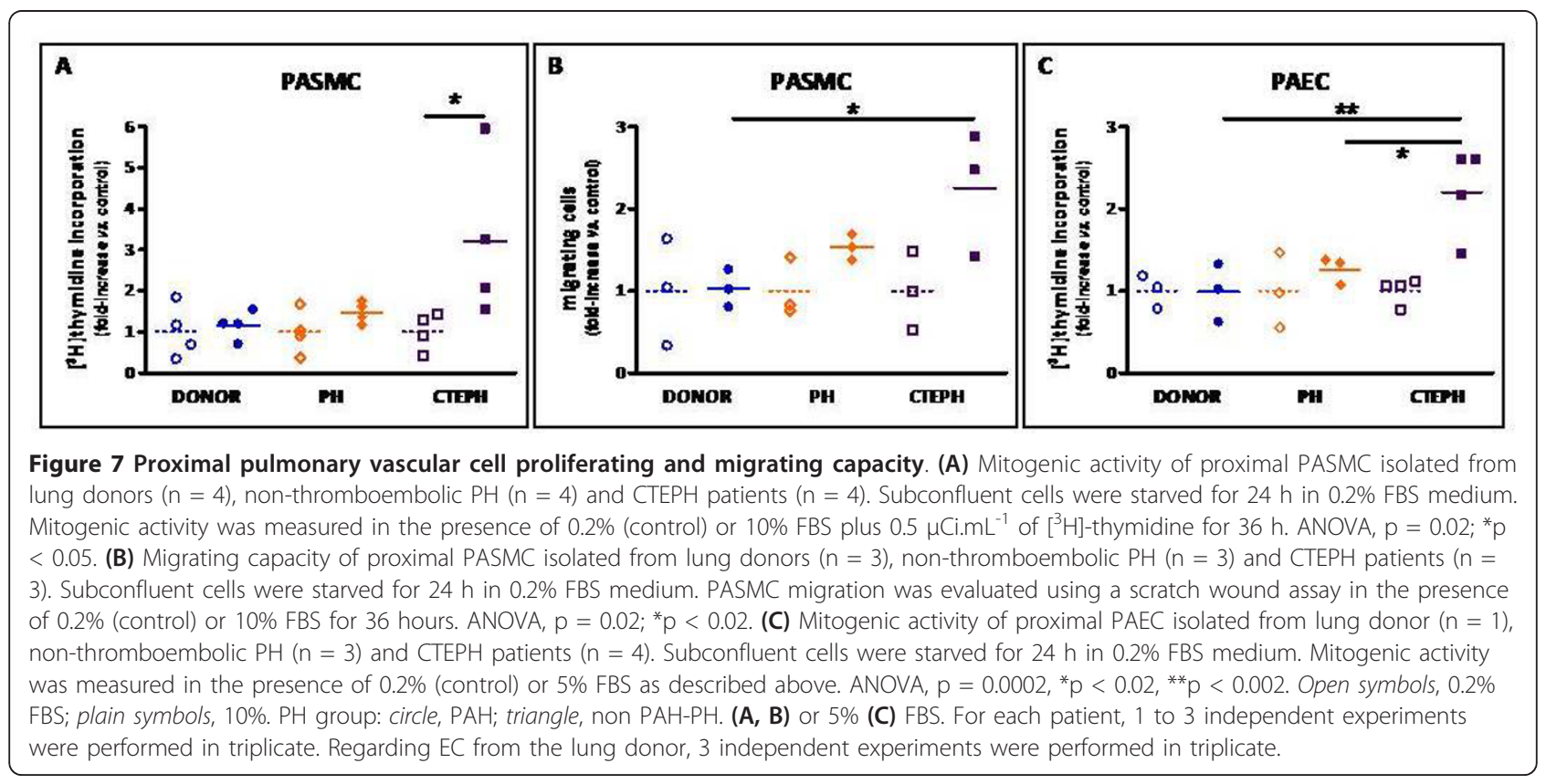



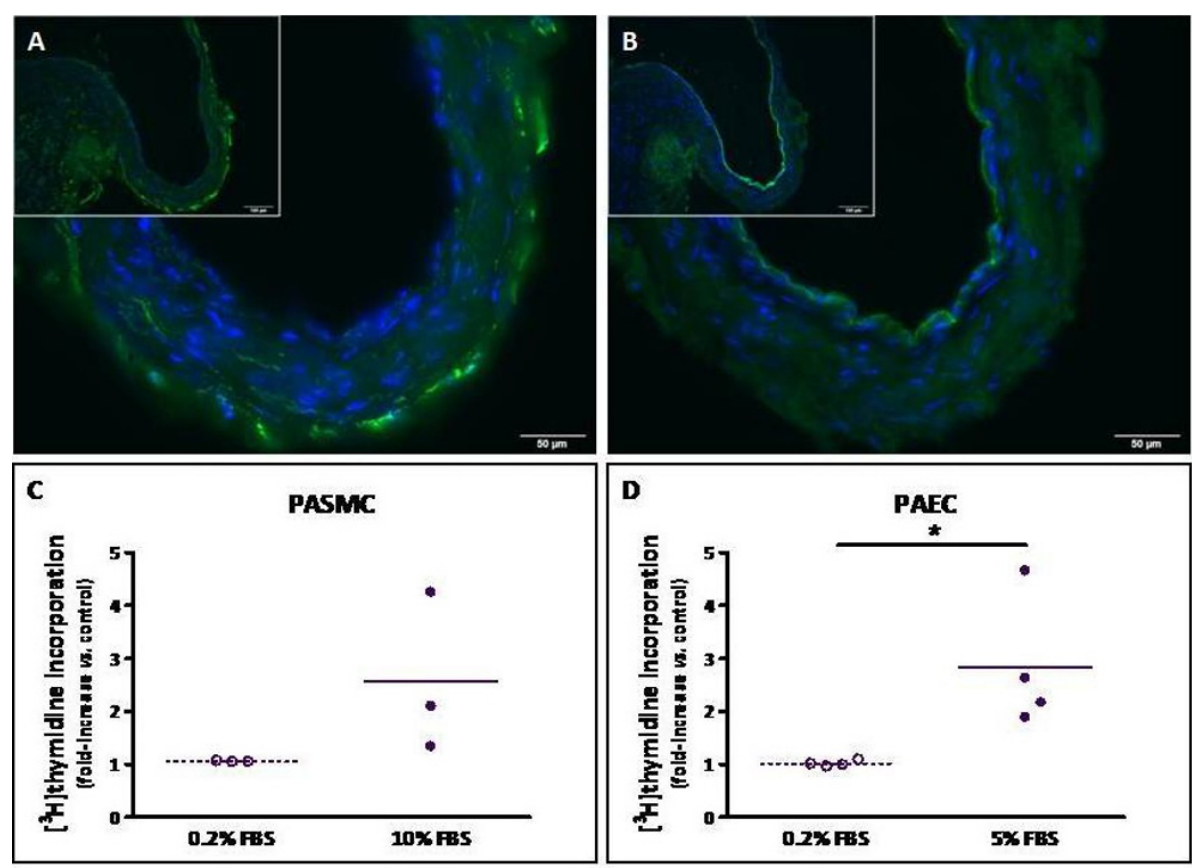

Figure 8 Cellular composition and in vitro proliferative capacities of PAEC and PASMC from (sub)segmental pulmonary arteries of CTEPH patients. Serial contiguous sections of (sub)segmental pulmonary arteries from CTEPH patients were stained with antibodies raised against $\alpha$-SMA (A) or CD31 (B). Nuclei were counterstained using DAPI (blue). Magnification: main image, $40 \times($ bar, $50 \mu \mathrm{m})$; insert, $20 \times($ bar, 100 $\mu \mathrm{m}$ ). Subconfluent cells were starved for $24 \mathrm{~h}$ in $0.2 \% \mathrm{FBS}$ medium. Mitogenic activity was measured in the presence of $0.2 \%$ (control) or $10 \%$ FBS (C) or $5 \%$ FBS (D) as described above. (D) ${ }^{*} p=0.03$.

protagonists have not been clearly identified. Few studies have focused on the implication of pulmonary artery cells in the pathogenesis of the disease. Lang and co-workers have investigated tissue plasminogen secretion by EC derived from main pulmonary arteries of patients with CTEPH [15]. Firth and Yao highlighted the presence of endothelial and multipotent mesenchymal progenitor cells in pulmonary vascular tissue of CTEPH patients $[16,17]$. Considering that the physiopathology of CTEPH remains incompletely understood, establishing well characterized primary cultures of proximal pulmonary vascular cells from CTEPH patients should be an asset to unravel the mechanisms resulting in the persistence of unresolved thrombi in CTEPH. PAEC express CD31 at their surface, vWF in WeibelPalade bodies and are capable of taking up ac-LDL, confirming the homogeneity of our PAEC primary cultures, as described elsewhere [18]. Consequently, the combination of a mild enzymatic digestion coupled to purification on CD31 antibody-conjugated magnetic beads can be validated to establish homogeneous PAEC primary cultures. Despite of differences between neointimal material from CTEPH and non-thromboembolic patients, both primary cultures of PASMC harbor SM differentiation marker expression including $\alpha$-SMA, desmin and SMMHC.

\section{PASMC proliferative phenotype}

Regarding pulmonary arterial tissue content in smooth muscle differentiation markers, expression of desmin, a marker of late smooth muscle differentiation, was significantly lower in CTEPH than in PH. By contrast, $\alpha$ SMA expression, a marker of early smooth muscle differentiation, was similar in both groups of patients, suggesting a potential switch of CTEPH-PASMC towards a proliferative phenotype. Moreover, both medial and $\mathrm{PH}$ PASMC concomitantly express $\alpha$-SMA and desmin or SMMHC, whereas neointimal CTEPH-PASMC mostly harbor $\alpha$-SMA labeling. In addition, neointima thickness of the proximal pulmonary arteries was significantly higher in CTEPH than in non-thromboembolic patients. Taken together, these findings could suggest that CTEPH-SMC likely derived from clusters of PASMC with a switched proliferative phenotype. Accordingly, dedifferentiation or phenotypic modulation of SMC has been widely depicted in various vascular wall diseases including atherosclerosis [19]. This process is accompanied by a down-regulation of several smooth muscle differentiation markers including myosin heavy chain, $\alpha$ actin, desmin, smoothelin, caldesmon and by an increase of their proliferating and migrating capacities in vitro [19]. In the present study, we have evidenced that neointima of proximal pulmonary arteries from CTEPH 
patients express less late SM differentiation markers and contain SMC with a proliferative phenotype, which display enhanced proliferating and migratory capacities in vitro. However, we cannot exclude that CTEPH-SMC may also derive from progenitor cells since Firth et al have identified a myofibroblast cell phenotype within the multipotent progenitor cell population isolated from CTEPH patients [16].

\section{Pulmonary vascular dysfunction}

Our results indicate a potential involvement of the vascular wall in the pathophysiological process of CTEPH, as suggested by in vitro increased proliferating and migrating capacity of proximal CTEPH-PASMC and enhanced mitogenic activity of proximal CTEPH-PAEC. By contrast, enhanced in vitro proliferating capacity of distal precapillary PASMC and PAEC has been described in PAH [20,21]. Hyperproliferative apoptosisresistant EC [22] and alterations of cellular bioenergetics of PAEC have been evidenced in idiopathic PAH [23]. Remodeling of the pulmonary vascular wall, characterized by intima and media hypertrophy, is a key process contributing to the formation of plexiform lesions observed in distal pulmonary vessels in PAH [24-26]. Endothelium dysfunction, accounted by hyper-proliferative CTEPH-PAEC, could contribute to PASMC migration and proliferation through PAEC protease-induced matrix impairment and PAEC-derived growth factors, respectively. As mentioned above, the hyperproliferative phenotype of both proximal and sub-segmental pulmonary vascular cells also suggest that these changes would not be only attributable to effects of thrombus-derived compounds, but also to cellular intrinsic modifications.

\section{Relevance of the study}

To date, few studies had focused on the pathophysiology of CTEPH. By establishing primary cultures of PAEC and PASMC derived from CTEPH patients, we aim to unravel the mechanisms potentially involved in the persistent obstruction of proximal pulmonary arteries following massive or recurrent pulmonary embolism. It appears that enhanced proliferation and/or migration of PAEC and PASMC could be involved in the progression of the disease. Although our results are mainly based on primary cell culture bypassing intercellular communications, shear stress and dynamic effects of blood flow, it remains an interesting tool to further understand the pathophysiology of CTEPH.

\section{Conclusion}

Modified proliferative and/or migratory responses of primary PASMC and PAEC in vitro, associated to a proliferative phenotype of CTEPH-PASMC suggest a dysfunction of pulmonary vascular cells in CTEPH, potentially involved in vascular remodeling.

\section{Additional material}

Additional file 1: Detailed Methods.

Additional file 2: Table Individual patient characteristics.

\section{Abbreviations}

a-SMA: a-smooth muscle actin; ac-LDL: acetylated-LDL; CTEPH: chronic thromboembolic pulmonary hypertension; FBS: fetal bovine serum; PAEC: pulmonary arterial endothelial cell; $\mathrm{PAH}$ : pulmonary arterial hypertension; PASMC: pulmonary arterial smooth muscle cell; PEA: pulmonary endarterectomy; SMMHC: smooth muscle myosin heavy chain; SPAP: systolic pulmonary arterial pressure; vWF: von Willebrand Factor.

\section{Acknowledgements}

This work was supported by research grants from Pfizer and from the Belgian Funds for Cardiac Surgery. MD is holder of the Actelion chair for Pulmonary Hypertension and of the GSK chair for Research and Education in pulmonary vascular pathology at the Katholieke Universiteit Leuven. The authors are grateful to W. Coosemans, W. Daenen, P. De Leyn, T. Lerut, P. Nafteux and F. Rega for their help and collaboration in collecting patient samples and to L. Vengethasamy for technical assistance.

\section{Author details}

${ }^{1}$ Center for Pulmonary Vascular Diseases, Respiratory Disease Department, Katholieke Universiteit and Universitaire Ziekenhuizen Leuven, Leuven, Belgium. ${ }^{2}$ Molecular Cell Biology Department, Katholieke Universiteit, Leuven, Belgium. ${ }^{3}$ Thoracic Surgery and Cardiac Surgery Department, Universitaire Ziekenhuizen Leuven, Leuven, Belgium. ${ }^{4}$ Cardiac Surgery Department, Universitaire Ziekenhuizen Leuven, Leuven, Belgium. ${ }^{5}$ Department of Pneumology; Universitaire Ziekenhuizen Leuven, Herestraat 49, B-3000 Leuven, Belgium.

\section{Authors' contributions}

MW has acquired, analyzed and interpreted the data, performed statistical analysis and drafted the manuscript. RQ has conceived and designed the research, acquired, analyzed and interpreted the data, performed statistical, handled supervision and made critical revision of the manuscript. AR has acquired the data. MRS and FW have made critical revision of the manuscript. DVR and BM have collected the human tissue specimens and made critical revision of the manuscript. MD has conceived and designed the research, handled funding and supervision and made critical revision of the manuscript. All authors read and approved the final manuscript.

\section{Competing interests}

The authors declare that they have no competing interests.

Received: 21 December 2011 Accepted: 27 March 2012 Published: 27 March 2012

\section{References}

1. Hoeper MM, Mayer E, Simonneau G, Rubin LJ: Chronic thromboembolic pulmonary hypertension. Circulation 2006, 113:2011-2020.

2. Arbustini E, Morbini P, D'Armini AM, Repetto A, Minzioni G, Piovella F, Vigano M, Tavazzi L: Plaque composition in plexogenic and thromboembolic pulmonary hypertension: the critical role of thrombotic material in pultaceous core formation. Heart 2002, 88:177-182.

3. Bonderman D, Turecek PL, Jakowitsch J, Weltermann A, Adlbrecht C, Schneider B, Kneussl M, Rubin LJ, Kyrle PA, Klepetko W, Maurer G, Lang IM: High prevalence of elevated clotting factor VIII in chronic thromboembolic pulmonary hypertension. Thromb Haemost 2003, 90:372-376.

4. Bonderman D, Wilkens H, Wakounig S, Schafers HJ, Jansa P, Lindner J, Simkova I, Martischnig AM, Dudczak J, Sadushi R, Skoro-Sajer N, Klepetko W, 
Lang IM: Risk factors for chronic thromboembolic pulmonary hypertension. Eur Resp J 2009, 33:325-331.

5. Lang I, Kerr K: Risk factors for chronic thromboembolic pulmonary hypertension. Proc Am Thorac Soc 2006, 3:568-570.

6. Bonderman D, Jakowitsch J, Adlbrecht C, Schemper M, Kyrle PA, Schonauer V, Exner M, Klepetko W, Kneussl MP, Maurer G, Lang I: Medical conditions increasing the risk of chronic thromboembolic pulmonary hypertension. Thromb Haemost 2005, 93:512-516.

7. Quarck R, Nawrot T, Meyns B, Delcroix M: C-reactive protein: a new predictor of adverse outcome in pulmonary arterial hypertension. J Am Coll Cardiol 2009, 53:1211-1218.

8. Bernard J, Yi ES: Pulmonary thromboendarterectomy: a clinicopathologic study of 200 consecutive pulmonary thromboendarterectomy cases in one institution. Hum Pathol 2007, 38:871-877.

9. Pusztaszeri MP, Seelentag W, Bosman FT: Immunohistochemical Expression of Endothelial Markers CD31, CD34, von Willebrand Factor, and Fli-1 in Normal Human Tissues. J Histochem Cytochem 2006, 54:385-395.

10. Tamura Y, Osuga Ji, Adachi H, Tozawa Ri, Takanezawa Y, Ohashi K, Yahagi N, Sekiya M, Okazaki H, Tomita S, lizuka Y, Koizumi H, Inaba T, Yagyu H, Kamada N, Suzuki H, Shimano H, Kadowaki T, Tsujimoto M, Arai H, Yamada N, Ishibashi S: Scavenger Receptor Expressed by Endothelial Cells I (SREC-I) Mediates the Uptake of Acetylated Low Density Lipoproteins by Macrophages Stimulated with Lipopolysaccharide. J Biol Chem 2004, 279:30938-30944.

11. Owens GK: Regulation of differentiation of vascular smooth muscle cells. Physiol Rev 1995, 75:487-517.

12. Theilmeier G, Quarck R, Verhamme P, Bochaton-Piallat ML, Lox M, Bernar H, Janssens S, Kockx M, Gabbiani G, Collen D, Holvoet P:

Hypercholesterolemia impairs vascular remodelling after porcine coronary angioplasty. Cardiovasc Res 2002, 55:385-395.

13. Quarck R, Berrou E, Magnier C, Bobe R, Bredoux R, Tobelem G, Enouf J, Bryckaert M: Differential up-regulation of Rap1a and Rap1b proteins during smooth muscle cell cycle. Eur J Cell Biol 1996, 70:269-277.

14. Sacks RS, Remillard CV, Agange N, Auger WR, Thistlethwaite PA, Yuan JX: Molecular biology of chronic thromboembolic pulmonary hypertension. Semin Thorac Cardiovasc Surg 2006, 18:265-276.

15. Lang IM, Marsh JJ, Olman MA, Moser KM, Schleef RR: Parallel analysis of tissue-type plasminogen activator and type 1 plasminogen activator inhibitor in plasma and endothelial cells derived from patients with chronic pulmonary thromboemboli. Circulation 1994, 90:706-712.

16. Firth AL, Yao W, Ogawa A, Madani MM, Lin GY, Yuan JXJ: Multipotent mesenchymal progenitor cells are present in endarterectomized tissues from patients with chronic thromboembolic pulmonary hypertension. Am J Physiol Cell Physiol 2010, 298:C1217-C1225.

17. Yao W, Firth AL, Sacks RS, Ogawa A, Auger WR, Fedullo PF, Madani MM, Lin GY, Sakakibara N, Thistlethwaite PA, Jamieson SW, Rubin LJ, Yuan JXJ: Identification of putative endothelial progenitor cells (CD34 + CD133 + Flk-1+) in endarterectomized tissue of patients with chronic thromboembolic pulmonary hypertension. Am J Physiol Lung Cell Mol Physiol 2009, 296:L870-L878.

18. Yan $Q$, Vernon RB, Hendrickson AE, Sage EH: Primary culture and characterization of microvascular endothelial cells from Macaca monkey retina. Investig Ophthalmol Vis Sci 1996, 37:2185-2194.

19. Owens GK, Kumar MS, Wamhoff BR: Molecular regulation of vascular smooth muscle cell differentiation in development and disease. Physiol Rev 2004, 84:767-801.

20. Dewachter L, Adnot S, Fadel E, Humbert M, Maitre B, Barlier-Mur AM, Simonneau G, Hamon M, Naeije R, Eddahibi S: Angiopoietin/Tie2 Pathway Influences Smooth Muscle Hyperplasia in Idiopathic Pulmonary Hypertension. Am J Resp Crit Care Med 2006, 174:1025-1033.

21. Eddahibi S, Guignabert C, Barlier-Mur AM, Dewachter L, Fadel E, Dartevelle P, Humbert M, Simonneau G, Hanoun N, Saurini F, Hamon M, Adnot S: Cross Talk Between Endothelial and Smooth Muscle Cells in Pulmonary Hypertension: Critical Role for Serotonin-Induced Smooth Muscle Hyperplasia. Circulation 2006, 113:1857-1864.

22. Masri FA, Xu W, Comhair SAA, Asosingh K, Koo M, Vasanji A, Drazba J, Anand-Apte B, Erzurum SC: Hyperproliferative apoptosis-resistant endothelial cells in idiopathic pulmonary arterial hypertension. Am J Physiol Lung Cell Mol Physiol 2007, 293:L548-L554.
23. Xu W, Koeck T, Lara AR, Neumann D, DiFilippo FP, Koo M, Janocha AJ, Masri FA, Arroliga AC, Jennings C, Dweik RA, Tuder RM, Stuehr DJ, Erzurum SC: Alterations of cellular bioenergetics in pulmonary artery endothelial cells. Proc Natl Acad Sci USA 2007, 104:1342-1347.

24. Blauwet LA, Edwards WD, Tazelaar HD, McGregor CG: Surgical pathology of pulmonary thromboendarterectomy: a study of 54 cases from 1990 to 2001. Hum Pathol 2003, 34:1290-1298.

25. Jamieson SW, Kapelanski DP, Sakakibara N, Manecke GR, Thistlethwaite PA, Kerr KM, Channick RN, Fedullo PF, Auger WR: Pulmonary endarterectomy: experience and lessons learned in 1,500 cases. Ann Thorac Surg 2003, 76:1457-1462.

26. Yi ES, Kim H, Ahn H, Strother J, Morris T, Masliah E, Hansen LA, Park K, Friedman PJ: Distribution of obstructive intimal lesions and their cellular phenotypes in chronic pulmonary hypertension. A morphometric and immunohistochemical study. Am J Respir Crit Care Med 2000, 162:1577-1586.

doi:10.1186/1465-9921-13-27

Cite this article as: Quarck et al: Characterization of proximal pulmonary arterial cells from chronic thromboembolic pulmonary hypertension patients. Respiratory Research 2012 13:27.

\section{Submit your next manuscript to BioMed Central and take full advantage of:}

- Convenient online submission

- Thorough peer review

- No space constraints or color figure charges

- Immediate publication on acceptance

- Inclusion in PubMed, CAS, Scopus and Google Scholar

- Research which is freely available for redistribution

Submit your manuscript at www.biomedcentral.com/submit
C Biomed Central 